\title{
Experimental study of IERSFDs for vibration reduction of gear transmissions
}

\author{
Kaihua Lu ${ }^{1}$, Lidong He ${ }^{2}$, Wei Yan ${ }^{3}$ \\ Beijing Key Laboratory of Health Monitoring and Self-Recovery for High-End Mechanical Equipment, \\ Beijing University of Chemical Technology, Beijing, 100029, China \\ ${ }^{2}$ Corresponding author \\ E-mail:1kaihualu1991@163.com, ${ }^{2} 1963 h e @ 163 . c o m,{ }^{3}$ yanwei0416@126.com
}

Received 1 October 2018; received in revised form 5 January 2019; accepted 22 January 2019 DOI https://doi.org/10.21595/jve.2019.20273

Check for updates

Copyright $(2019$ Kaihua Lu, et al. This is an open access article distributed under the Creative Commons Attribution License, which permits unrestricted use, distribution, and reproduction in any medium, provided the original work is properly cited.

\begin{abstract}
Integral elastic ring squeeze film damper (IERSFD) is proposed to reduce and isolate the vibration of the gear transmissions. IERSFD offers the performance of a low radial stiffness and high squeeze film damping. This paper presents a mechanical model of an IERSFD elastic damping support and a single-degree-of-freedom vibration isolation system for the gear system. An open single-stage spur gear system was built to experimentally study the vibration characteristics of gear transmissions with rigid supports and with IERSFD elastic damping supports filled with damping fluids of different viscosities. The experimental results show that the IERSFD can effectively reduce the peak vibration acceleration of the gear shafts and can guarantee the smooth operation of the gear assembly over a range of speeds. This work shows that an IERSFD can reduce the shock and vibration of the gears' meshing. It effectively attenuates vibration for most of the gears' frequency components. Within a limited viscosity range, the vibration reduction is more effective with the higher-viscosity IERSFD damping fluids tested.
\end{abstract}

Keywords: integral elastic ring squeeze film damper (IERSFD), gear transmissions, elastic damping support, vibration reduction.

\section{Introduction}

Geared transmissions are one of the most widely used power transmission methods in mechanical engineering. Because of the internal excitations caused by time-varying meshing stiffness and gear errors, gear systems are prone to significant vibration and noise problems, especially when there are manufacturing and installation errors. Significant vibrations can cause damages to the equipment. Noise caused by vibration can also affect the health of operation staff. Therefore, it is of great engineering value to study the technology to reduce vibration and noise in gear transmissions [1]. The vibration characteristics of gear system are rather complicated, because it is composed of multiple components such as the meshing frequency with its high harmonics and the rotating frequency with its low harmonics [2].

Scholars have done a great deal of research on vibration reduction methods for gear transmissions. Their developed gearbox vibration reduction methods can be divided into vibration source reduction, and passive vibration reduction through vibration absorption. Vibration source reduction reduces the source of gears' vibration by optimizing the parameters and modifying the gear teeth during the gear design process [3-5]. The process of vibration source reduction is complicated by its high manufacturing cost and large computational effort [6,7]. Passive vibration reduction for a gear transmission uses energy-consuming devices to dissipate vibration energy. For example, a damping ring and viscoelastic damping layer in the gear can absorb the vibration energy of the gear [8-10]. However, it is necessary to add the damping material over a large area, increasing the weight and size of a gearbox. Sutton et al. [11] used hysteresis regulators to control the vibration of the gear and achieved a decrease of 30-40 dB for the 250 to $1250 \mathrm{~Hz}$ frequency range, but the damping effect was inadequate in the 500 to $800 \mathrm{~Hz}$ frequency range. Guan et al. [12] used piezoelectric actuators to counteract the vibration and noise of the gearbox. By improving the control algorithm, the vibrations were reduced by $8-13 \mathrm{~dB}$, and the noise at the 
meshing frequency was reduced by $5-8 \mathrm{~dB}$. However, the range for which the vibration frequencies had been reduced was very limited, and the control algorithm was complex. Huang et al. [13] obtained a certain damping effect by installing a viscous damper on the gear shaft, but their damper required a large amount of space and was unsuitable for a gearbox requiring compact shaft structure.

Squeeze film dampers (SFD) are often used to reduce the rotor vibration as it passes through its critical speed. However, the traditional squirrel cage-SFD has many problems such as large space occupation, difficult assembly, and vulnerability to fatigue. In addition, the oil film force of a SFD is nonlinear. If the damper design is unreasonable, the rotor vibration will increase instead of decrease. To overcome these shortcomings, an integral elastic ring squeeze film damper (IERSFD) was designed and used to reduce and isolate vibrations generated by gear mesh excitation.

Unlike the unbalanced excitation of the rotor, the vibration of the gear system is mainly caused by gears' meshing process. The dynamic excitation of the gear system is transmitted to the box mainly through the bearing. Measures taken at the bearing position can effectively attenuate the vibration transmission [14]. The IERSFD described in this paper is designed to control the vibration of gear shafts and isolate the vibration excitation through the bearings to the supporting structure. IERSFD has both the performance of a low radial stiffness and high squeeze film damping, which can provide viscous damping to reduce the lateral vibration amplitude of the gear system and to isolate vibration transmitted to other structural parts. IERSFD has segmented squeeze film regions that can inhibit the generation of nonlinear oil film stiffness. Its system-level advantages include its simple structure and straightforward assembly. Dimethyl silicone oil is a kind of silicon-based liquid with high viscosity and good thermal stability, and it is often used as a damping fluid for vibration absorption structures. In this study, dimethyl silicone oil is used as the IERSFD damping fluid.

For the experimental work described in this paper, four sets of IERSFD elastic damping support structures were designed and manufactured, and a single-stage involute spur gear transmission system was built. The vibration reduction characteristics of gear shafts with IERSFD were studied by comparing the vibrations of the gear system with the IERSFD elastic damping support filled with different viscosity damping fluids, to the vibrations of a gear system fabricated with the same layout and the same gear ratio and gear meshing characteristics, but a solid structure and without the damping structures. This latter case serves as a base case.

\section{Integral elastic ring squeeze film dampers}

\subsection{The structure of an IERSFD}

The IERSFD described here uses a three-layer oil film, double elastic ring structure, as shown in Fig. 1. The oil film gap is $0.3 \mathrm{~mm}$. Each layer of oil film is circumferentially divided into four sections, and the twelve sections of the three-layer oil film are staggered. The thickness of each elastic ring is $1 \mathrm{~mm}$, and its axial width is $10 \mathrm{~mm}$. The oil storage cavity on both sides of the elastic ring is used for storing the damping fluid, and is sealed by the sealing cap and O-type rubber rings. The elastic ring structure reduces the radial stiffness of IERSFD, and the oil film absorbs the vibration energy.

The outer race of the IERSFD is a transition fit with the bearing block. The inner race of the IERSFD has an interference fit with the outer race of the ball bearing. The IERSFD elastic damping support assembled with IERSFD, bearing block and ball bearing is shown in Fig. 2 . The manufactured IERSFD is shown in Fig. 3. 

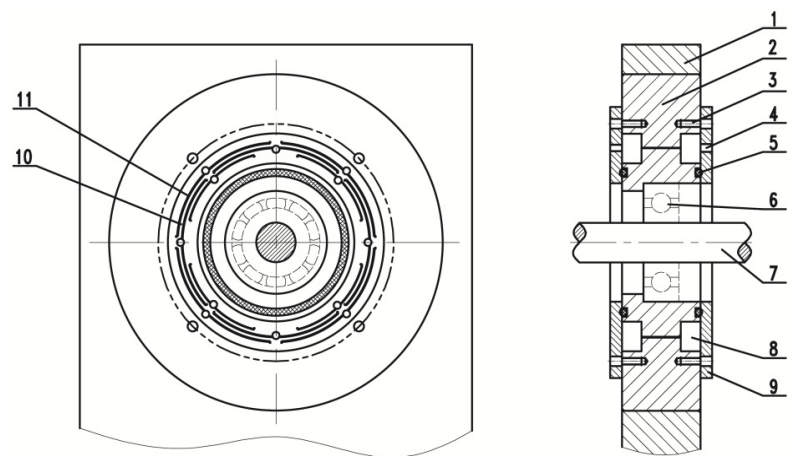

Fig. 1. The structure of the IERSFD and its assembly diagram with the shaft: $1-$ bearing block, 2 - IERSFD, 3 - bolt hole, 4 - grease hole, 5 - O-type rubber ring, 6 - ball bearing, 7 - shaft; 8 - oil storage cavity, 9 - sealing cap, 10 - elastic ring, 11 - squeeze film region

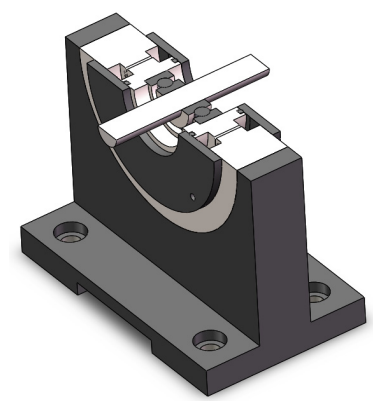

Fig. 2. IERSFD elastic damping support

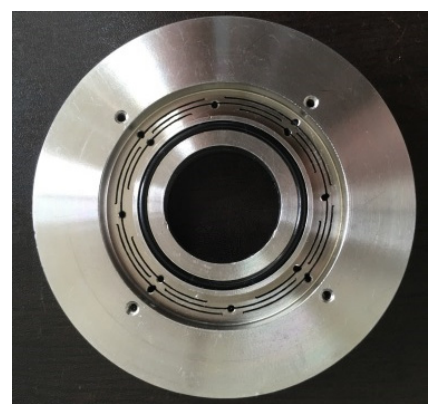

Fig. 3. The manufactured IERSFD

\subsection{The IERSFD mechanical model}

The IERSFD support is modeled as a set of dampers and springs with a mass at the shaft location. The oil film of IERSFD has a gap of $0.3 \mathrm{~mm}$, which is large as compared to a similar-diameter journal bearing's gap. When there is no oil supply pressure, the oil film stiffness can be ignored, and only the damping force generated by squeezing the oil film is considered. Also, the damping of ball bearing is negligible, so only its stiffness is considered. The mechanical model of IERSFD support system is shown in Fig. 4.

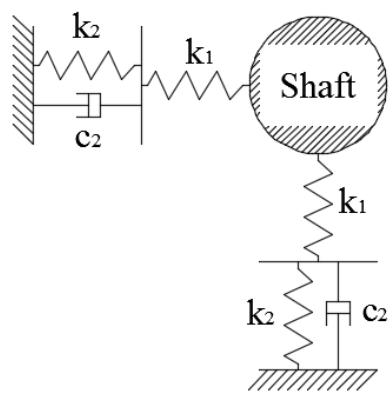

Fig. 4. The mechanical model of IERSFD support system

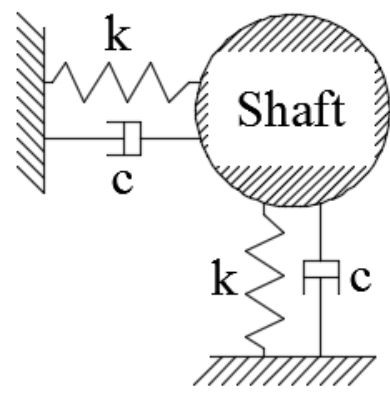

Fig. 5. The simplified mechanical model of IERSFD support system

In Fig. $4, k_{1}$ is the stiffness of the ball bearing, and $k_{2}$ and $c_{2}$ are the stiffness and damping coefficient of the IERSFD respectively. The stiffness of the ball bearing and the IERSFD are in series, and the assembly stiffness is $k=\left(k_{1} k_{2}\right) /\left(k_{1}+k_{2}\right)$. As $k_{2} \ll k_{1}$, the introduction of the IERSFD reduces the overall stiffness of the bearing support system. The damping coefficient of 
the assembly needs to include the damping of ball bearing, but in this work the ball bearing has negligible damping compared to the IERSFD itself: $c=c_{2}$. This support system damping coefficient is greatly increased by adding the IERSFD. The simplified mechanical model of IERSFD support system is shown in Fig. 5.

\section{Vibration model of the assembled gear system}

For a convenient analysis, a simplified vibration model of gear system was developed. This is shown in Fig. 6. Among them, the meshing gear pair can be simplified as the concentrated mass of the vibration source, and the gearbox can be simplified as another concentrated mass being excited. The bearing between the gear and box can be regarded as a spring with a certain stiffness $k$ and damping $c$. Generally, the gearbox is connected with the engine base elastically, and the shaft alignment requires that the stiffness value $k^{\prime}$ should be large [15]. The dynamic excitation of the gear system is mainly transmitted to the box through the bearing. Taking measures in the bearing part can effectively reduce the vibration transmission. According to the vibration theory [16], in order to reduce the vibration response of the gearbox, it is generally necessary to reduce the radial stiffness $k$ of the bearing appropriately and increase the bearing damping $c$. As a result, the natural frequency of the gear system is reduced, and the vibration transmission of the system is decreased.

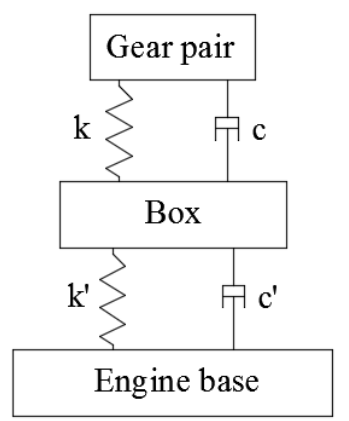

Fig. 6. Vibration model of gear system

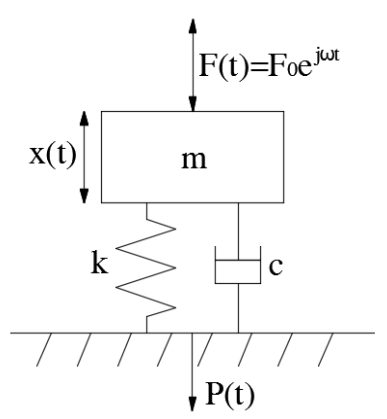

Fig. 7. Vibration isolation system with a single degree of freedom in damping

Considering the vibration of the gearbox as an investigation index, a single-degree-of-freedom vibration isolation system in damping for the gear system is established, as shown in Fig. 7.

The equation of motion of this system is:

$m \ddot{x}+c \dot{x}+k x=F_{0} e^{j \omega t}$,

where $m, k, c$ denote the mass, stiffness and damping of the vibration isolation system, respectively. The amplitude of the equation of motion mentioned above is:

$x_{0}=\left|\frac{F_{0}}{k} \frac{1}{\left(1-z^{2}+j 2 \zeta z\right)}\right|$,

where $\omega_{0}=\sqrt{k / m}$ denotes the natural frequency of the system. The variable $z=\omega / \omega_{0}$ is the frequency ratio, and $\zeta=c /(2 \sqrt{m k})$ is the damping ratio of the system. The force transmitted to the box is written as:

$P=c \dot{x}+k x$.

The force amplitude is: 
$P_{0}=\left|j \omega c x_{0}+k x_{0}\right|$

This leads to the vibration transmission coefficient of the system:

$T=\left|\frac{P_{0}}{F_{0}}\right|=\left|\frac{1}{k} \frac{j \omega c+k}{\left(1-z^{2}+j 2 \zeta z\right)}\right|=\frac{\sqrt{1+(2 \zeta z)^{2}}}{\sqrt{\left(1-z^{2}\right)^{2}+(2 \zeta z)^{2}}}$.

According to Eq. (5), when the excitation frequency $\omega$ is much larger than the natural frequency of the system $\omega_{0}$, the vibration transmission coefficient of the system is less than 1 , and the system has the vibration isolation effect. The gear meshing vibration and its high harmonics are all high-frequency components, which are much larger than the natural frequencies of the gear system. Therefore, the vibration isolation measure is effective. In addition, the introduction of damping $c$ can limit the resonance of gear system.

\section{Introduction of experimental setup}

\subsection{Two support structures}

To study the vibration reduction characteristics of gear shafts with an IERSFD, two support structures were designed: rigid support and IERSFD elastic damping support, as shown in Fig. 8. The rigid support structure includes bearing block, rigid sleeve and ball bearing. The IERSFD support structure consists of a bearing block, IERSFD, ball bearing, O-type rubber ring and sealing cap. When using the IERSFD elastic damping support, dimethyl silicone oil with viscosity of $500 \mathrm{cs}, 1000 \mathrm{cs}$ and $5000 \mathrm{cs}$ was added to the oil storage cavity respectively. By comparing the vibration of the gear shafts under the two support structures, the vibration reduction characteristics of gear shafts with IERSFD are studied.

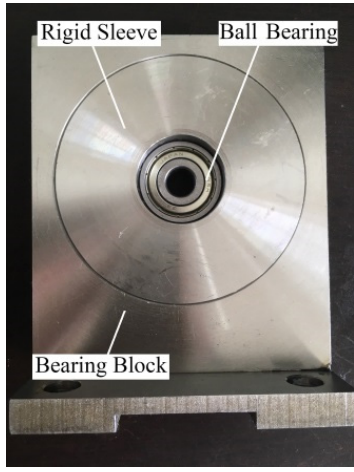

a) Rigid support

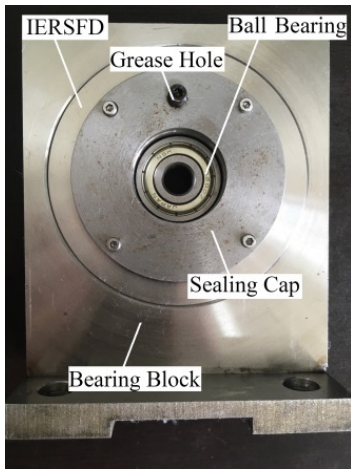

b) IERSFD elastic damping support

Fig. 8. Two support structures

\subsection{Test rig design}

The experimental setup for testing of gear vibration reduction with the IERSFD is shown in Fig. 9. It is a single-stage involute spur gear system. Technical data for the test gears are listed in Table 1. The driving shaft and driven shaft are $10 \mathrm{~mm}$ in diameter. The driving shaft span is $440 \mathrm{~mm}$, and the driven shaft $260 \mathrm{~mm}$. The shaft is driven by a DC variable frequency motor. To reduce the influence of motor vibration on the dynamic characteristics of the gear transmission system, a flexible coupling was used. The gear pair is lubricated by dripping oil during the experiment.

A LC-8008 fault diagnosis system was used for the vibration tests. The system has eight input channels, and can analyze and store vibration signal data. Vibration signals are collected by the 
acceleration sensor mounted on the bearing block, and the vibration along the horizontal direction of the two shafts' bearing blocks is measured. The photoelectric sensor was used to measure the shaft speed. The analysis frequency of the LC-8008 was set to $2000 \mathrm{~Hz}$, and the number of sampling points per period used was 1024 .

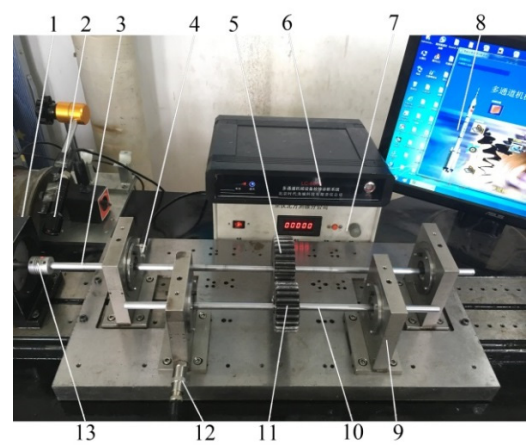

Fig. 9. Gear test rig: 1 - motor, 2 - photoelectric sensor, 3 - driving shaft, 4 -acceleration sensor 1 , 5 - driving gear, 6 - acquisition system LC-8008, 7 - motor speed controller, 8 - computer, 9 - IERSFD elastic damping support, 10 - driven shaft, 11 - driven gear, 12 - acceleration sensor 2,13 - flexible coupling

Table 1. Technical data for the test gears

\begin{tabular}{|c|c|}
\hline Gear parameters & Value \\
\hline Number of driving gear teeth $Z_{1}$ & 30 \\
\hline Number of driven gear teeth $Z_{2}$ & 20 \\
\hline Gear ratio $i$ & $2 / 3$ \\
\hline Gear modulus $m /(\mathrm{mm})$ & 3 \\
\hline Pressure angle $\alpha /\left(^{\circ}\right)$ & 20 \\
\hline Tooth thickness of driven gear $b_{2} /(\mathrm{mm})$ & 30 \\
\hline Tooth thickness of driving gear $b_{1} /(\mathrm{mm})$ & 28 \\
\hline Theoretical center distance $d /(\mathrm{mm})$ & 75 \\
\hline
\end{tabular}

\section{Results and discussion}

\subsection{Analysis of gear shafts' vibration suppression with IERSFD}

By adjusting the speed controller, the driving shaft speed $n_{1}$ was set in the range from $900 \mathrm{r} / \mathrm{min}$ to $2200 \mathrm{r} / \mathrm{min}$ respectively. The driven shaft speed, for those driving shaft speeds, was $n_{2}$ from $1350 \mathrm{r} / \mathrm{min}$ to $3300 \mathrm{r} / \mathrm{min}$, respectively.

The vibration of the gear shafts was measured both for the base case of installation on rigid supports and the test case with the IERSFD elastic damping supports filled with the 500cs viscosity damping fluid. The data was recorded at driving shaft speed increments of $100 \mathrm{r} / \mathrm{min}$. Figs. 10(a) and 10(b) show the vibration acceleration peaks of the two shafts' measuring points under two different types of supports.

As shown in Fig. 10, the vibration of the gear shafts increases with increasing rotational speed. Compared to the rigid support base case, the vibration amplitude of each measuring point is reduced with the IERSFD elastic damping support. It can be seen that the vibration reduction characteristics of the gear shafts are useful over a range of speeds after installing IERSFD elastic damping supports. The IERSFD support can effectively guarantee the smooth operation of the gear transmission system over a large range of speeds. Considering the vibration data from the measured point on driving shaft when $n_{1}=1200 \mathrm{r} / \mathrm{min}$ as an example, when the rigid support is changed to IERSFD support, the peak of vibrational acceleration was reduced from $5.25 \mathrm{~m} / \mathrm{s}^{2}$ to $2.82 \mathrm{~m} / \mathrm{s}^{2}$, for a decrease of $46.3 \%$. 
To further understand the vibration reduction characteristics of the IERSFD elastic damping support on the gear shaft, the time and frequency domain waveforms for each measuring point were extracted. Due to space limitations, time and frequency domain waveforms for two measuring points are analyzed when $n_{1}=1200 \mathrm{r} / \mathrm{min}$, as shown in Figs. 11 and 12.

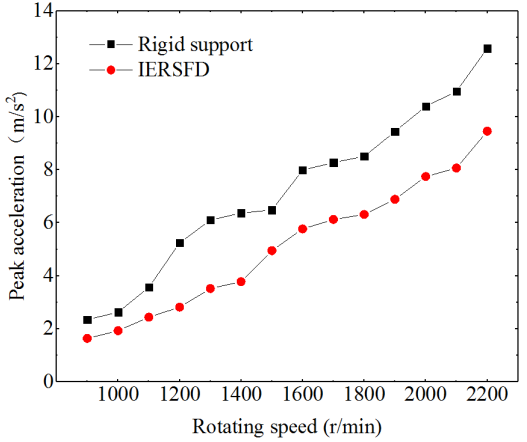

a) Comparison of driving shaft's measuring point

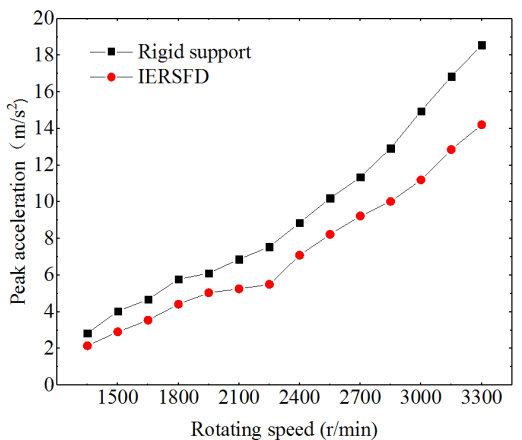

b) Comparison of driven shaft's measuring point

Fig. 10. Vibration comparison under two kinds of supports

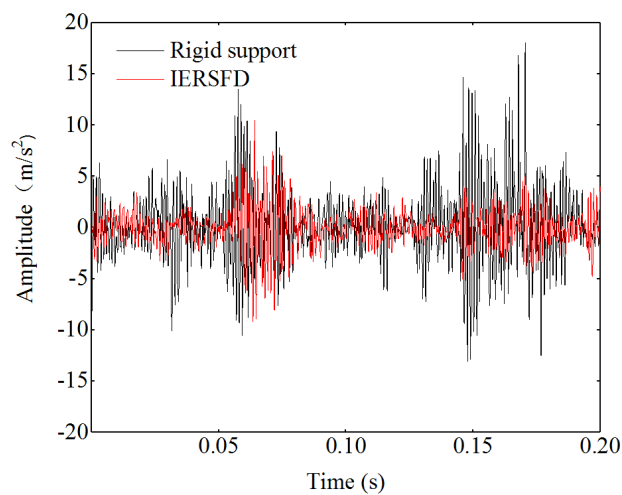

a) Time domain waveform

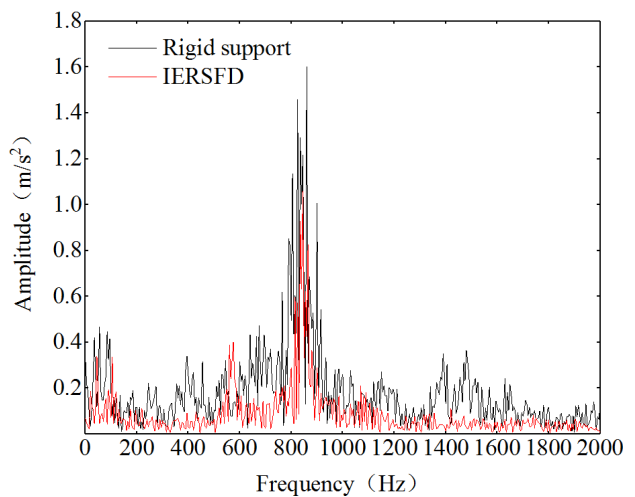

b) Frequency spectrum

Fig. 11. Comparison of vibration of driving shaft's measuring point

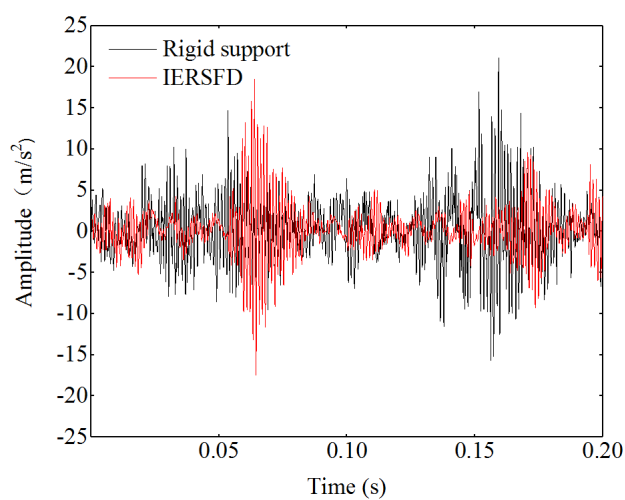

a) Time domain waveform

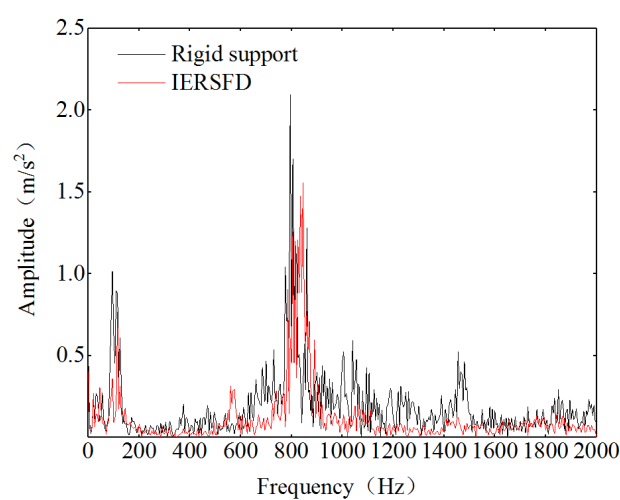

b) Frequency spectrum

Fig. 12. Comparison of vibration of driven shaft's measuring point

As can be seen from the time domain waveforms shown in Figs. 11(a) and 12(a), the modulation phenomenon in the time domain waveform decreases to a certain extent after the rigid support is replaced by an IERSFD support. This indicates that the IERSFD elastic damping 
support can inhibit the shock and vibration of the gears' meshing.

In Figs. 11(b) and 12(b), the frequency spectrum contains many frequency components. After installing the IERSFD support, the vibration of most frequency components is attenuated, indicating that IERSFD has a good vibration suppression of the gear shaft in a wide frequency range. The meshing frequency of the gear system is $f_{r}=Z_{1} n_{1} / 60=Z_{2} n_{2} / 60=600 \mathrm{~Hz}$, but the vibration amplitude of the meshing frequency is small. However, the vibrations in the vicinity of $90 \mathrm{~Hz}$ and $820 \mathrm{~Hz}$ are large, with a wide frequency band. According to the vibration theory [17], this is a resonance modulation phenomenon of the gear shaft. When the rigid support is replaced by the IERSFD support, the vibration at those frequency components is significantly reduced.

For the sake of a clear comparison, frequency spectrum ranges between 0-200 Hz, and $700-900 \mathrm{~Hz}$ are shown in Figs. 13 and 14, respectively. Tables 2, 3 list the vibration data at the frequency components which have large vibration amplitude.

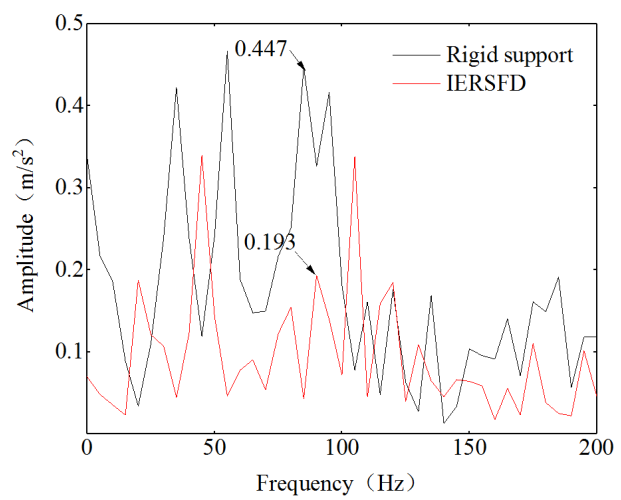

a) Frequency spectrum of driving shaft

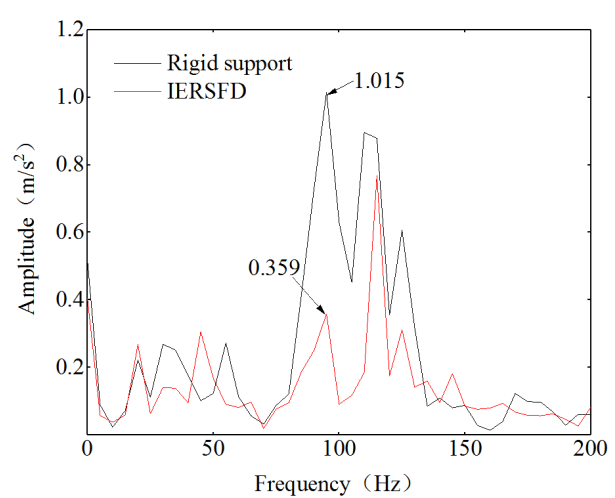

b) Frequency spectrum of driven shaft

Fig. 13. Frequency spectrum ranges between $0-200 \mathrm{~Hz}$

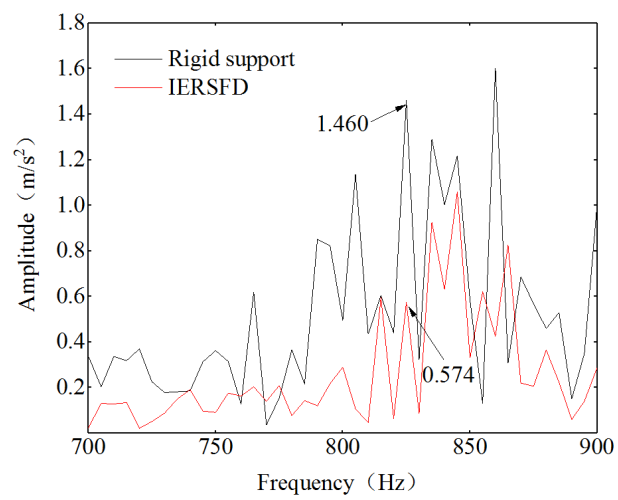

a) Frequency spectrum of driving shaft

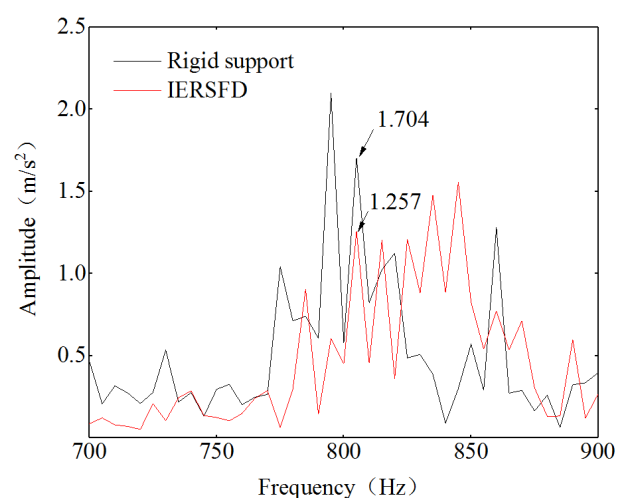

b) Frequency spectrum of driven shaft

Fig. 14. Frequency spectrum ranges between $700-900 \mathrm{~Hz}$

Table 2. Vibration data with different supports (driving shaft)

\begin{tabular}{|c|c|c|c|}
\hline \multirow{2}{*}{ Frequency $(\mathrm{Hz})$} & \multicolumn{2}{|c|}{ Vibration amplitude (m/s $\left.\mathrm{s}^{2}\right)$} & \multirow{2}{*}{ Decrease (\%) } \\
\cline { 2 - 3 } & Rigid support & IERSFD support & \\
\hline 90 & 0.447 & 0.193 & 56.8 \\
\hline 820 & 1.460 & 0.574 & 60.7 \\
\hline
\end{tabular}

The experimental results above show that the vibration amplitude at these frequency points decreases considerably. Considering the driven shaft's vibration at $90 \mathrm{~Hz}$ as an example, when the rigid support is changed to the IERSFD support, the vibration amplitude is reduced from 
$1.015 \mathrm{~m} / \mathrm{s}^{2}$ to $0.359 \mathrm{~m} / \mathrm{s}^{2}$, thus having a decrease of $64.6 \%$.

Table 3. Vibration data with different supports (driven shaft)

\begin{tabular}{|c|c|c|c|}
\hline \multirow{2}{*}{ Frequency $(\mathrm{Hz})$} & \multicolumn{2}{|c|}{ Vibration amplitude $\left(\mathrm{m} / \mathrm{s}^{2}\right)$} & \multirow{2}{*}{ Decrease (\%) } \\
\cline { 2 - 3 } & Rigid support & IERSFD support & \\
\hline 90 & 1.015 & 0.359 & 64.6 \\
\hline 820 & 1.704 & 1.257 & 26.2 \\
\hline
\end{tabular}

\subsection{Vibration reduction characteristics based on the damping fluid's viscosity}

The above experimental results show that IERSFD elastic damping support has good vibration attenuation performance for the gear transmission system. The influence of the damping fluid's viscosity on the vibration reduction characteristics of the IERSFD was also explored.

The motor speed was set from $900 \mathrm{r} / \mathrm{min}$ to $2200 \mathrm{r} / \mathrm{min}$. The vibration data of gear shafts equipped with the IERSFD elastic damping support filled with two other viscosity damping fluids $(1000 \mathrm{cs}, 5000 \mathrm{cs})$ were measured. Figs. 15, 16 show the peak of vibrational acceleration of the driving shaft and driven shaft for these different damping fluid viscosities.

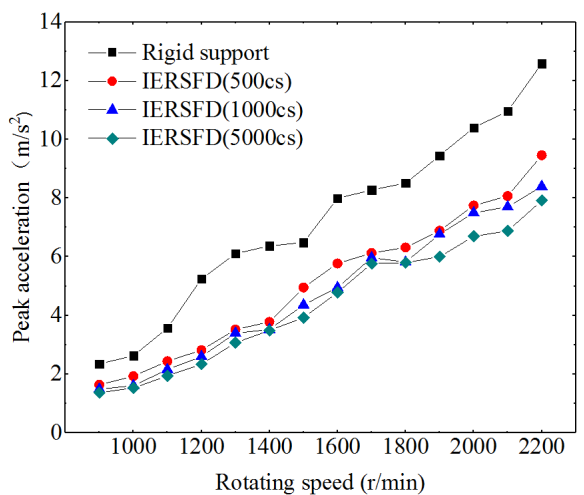

Fig. 15. Comparison of driving shaft's measuring point

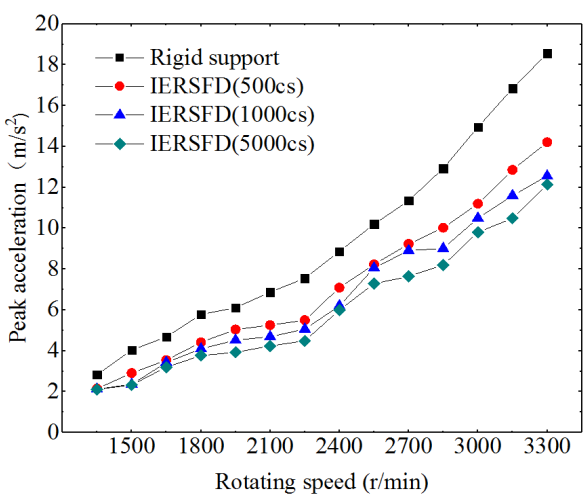

Fig. 16. Comparison of driven shaft's measuring point

According to the data in Figs. 15, 16, it can be seen that within a limited range of viscosity, as the viscosity of IERSFD damping fluid increases, the decreasing reduction of gear shafts' vibration improves. Taking the measuring point on the driving shaft as an example, when the motor speed is $1200 \mathrm{r} / \mathrm{min}$, the vibration under the rigid support is $5.25 \mathrm{~m} / \mathrm{s}^{2}$. As the viscosity of IERSFD damping fluid increases from $500 \mathrm{cs}$ to $1000 \mathrm{cs}$ and then to $5000 \mathrm{cs}$, the vibration amplitude decreases from $2.82 \mathrm{~m} / \mathrm{s}^{2}$ to $2.6 \mathrm{~m} / \mathrm{s}^{2}$ and then to $2.34 \mathrm{~m} / \mathrm{s}^{2}$, respectively, resulting in a decrease from $46.3 \%$ to $50.5 \%$ and then to $55.4 \%$.

\section{Conclusions}

Integral elastic ring squeeze film damper (IERSFD) was designed, and the application of IERSFD in the vibration control of gear shafts was experimentally studied.

1) IERSFD support can effectively reduce and isolate the vibration of the gear shaft caused by the gear mesh excitation.

2) Comparing IERSFD's vibration reduction characteristics at different speeds, the IERSFD elastic damping support can effectively guarantee significantly smooth operation of the gear transmission over a range of speeds.

3) The IERSFD support can improve the shock load characteristics of the gears' meshing.

4) The IERSFD support has good vibration attenuation effect on most frequency components in the gear transmission. 
5) Within a limited viscosity range, the vibration reduction is more effective with the higher-viscosity IERSFD damping fluids tested.

\section{Acknowledgements}

This work is supported by the National Basic Research Program of China (2012CB026000) and Key Laboratory Fund for Ship Vibration and Noise (614220406020717).

\section{References}

[1] Xiao W. Q., Huang Y. X., Li W., et al. Influence of particle damper configurations on the dynamic characteristic for gear transmission system. Journal of Mechanical Engineering, Vol. 53, Issue 7, 2017, p. 1-12.

[2] Ding K., Zhu X. Y., Chen Y. H. Typical fault vibration characteristics and diagnosis strategy of gearbox. Journal of Vibration and Shock, Vol. 20, Issue 3, 2001, p. 7-12.

[3] Yuan Z., Sun Z. L., Wang D., et al. GA-based optimum profile modification of spur gears for vibration damping. Journal of Northeastern University (Natural Science), Vol. 31, Issue 6, 2010, p. $873-876$.

[4] Li H. K., Guo C., Fang S. L., et al. Optimization design method for gearbox's vibration and noise reduction. Journal of Vibration and Shock, Vol. 32, Issue 17, 2013, p. 150-154.

[5] Shao C. J., Sun T., Shen Y. W., et al. A study on vibration depression of gear system by modification reanalysis of structural dynamics. Journal of Aerospace Power, Vol. 13, Issue 3, 1998, p. 305-309.

[6] Subramanian R. B., Srinivasan K. Vibration analysis of an influence of groove in the bottom land of a spur gear. Journal of Vibration and Control, Vol. 20, Issue 6, 2014, p. 847-858.

[7] Kim S. J., Lee S. K. Experimental identification on a gear whine noise in the axle system of a passenger van. International Journal of Automotive Technology, Vol. 8, Issue 1, 2007, p. 75-82.

[8] Wang Q. Y., Cao D. Q., Yang J. B. Axial vibration reduction characteristics of a gear system with a damping ring. Journal of Vibration and Shock, Vol. 32, Issue 6, 2013, p. 190-194.

[9] Zhong Y. T., Wang L. Q., Li W. L. Study on vibration reduction of gear drives based on damping technology. Journal of Mechanical Transmission, Vol. 35, Issue 11, 2011, p. 17-20.

[10] Mao B. Q., Lin L., Cao T. J. Study on reducing vibration and noise of the gear transmissions by using damped ring. Journal of Machine Design and Research, Vol. 21, Issue 1, 2005, p. 46-49.

[11] Sutton T. J., Elliott S. J., Brennan M. J., et al. Active isolation of multiple structural waves on a helicopter gearbox support strut. Journal of Sound and Vibration, Vol. 205, Issue 1, 1997, p. 81-101.

[12] Guan Y. H., Lim T. C., Shepard W. S., et al. Experimental study on active vibration control of a gearbox system. Journal of Sound and Vibration, Vol. 282, Issue 3, 2005, p. 713-733.

[13] Huang X. J., He L. D., Xia X. R., et al. Experimental study of viscous damper vibration reduction technology of gear shafting. Journal of Mechanical Transmission, Vol. 39, Issue 2, 2015, p. 99-103.

[14] Dai G. H., Yu X. H., Yin X. M., et al. The applied research of damping supporting structure in the gearbox. Ship Science and Technology, Vol. 36, Issue 9, 2014, p. 141-145.

[15] Wang G. Z., Sun P. L., Fang K. X. A research on the reduction of vibration and noise of the gearbox by using damping alloys. Journal of Jiangsu University of Science and Technology (Natural Science Edition), Vol. 8, Issue 3, 1994, p. 14-20.

[16] Vance J., Zeidan F., Murphy B. Machinery Vibration and Rotordynamics. First Edition, John Wiley and Sons Inc., New Jersey, 2010.

[17] Ding K., Li W. H., Zhu X. Y. Gears and Gearbox Fault Diagnosis Practical Technology. First Edition, Machinery Industry Press, Beijing, 2005.

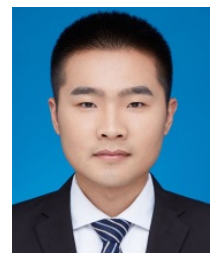

Kaihua Lu received his B.S. degree in Process Equipment and Control Engineering Department of Tianjin University of Science and Technology in 2014. Now he studies for his Ph.D. degree in Diagnosis and Self-recovery Engineering Research Center of Beijing University of Chemical Technology. His research interests are vibration control of pipeline and rotating machinery. 
Lidong He is a Ph.D. supervisor at Beijing University of Chemical Technology. His research interests are rotor automatic balancing technology, sealing technology and fault diagnosis.

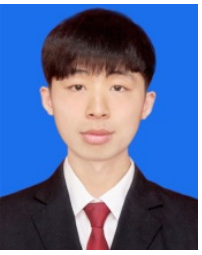

Wei Yan, a Ph.D. student in Diagnosis and Self-recovery Engineering Research Center of Beijing University of Chemical Technology. His research interests are vibration control of pipeline and rotating machinery. 